\title{
The Threat Posed to Tall Glass Curtain Walled Buildings in Urban Areas During Typhoons
}

\author{
Brian E. Lee \\ Department of Civil Engineering, University of Portsmouth, Portsmouth, PO1 3QL, UK
}

\section{INTRODUCTION}

Typhoons which have their origins in the warm waters of the Northwest Pacific are usually carried westward by the prevailing winds and may make landfall near any of the rapidly-developing cities of the south east asian region. In that event, massive economic loss comparable to that caused by Hurricane Andrew in Florida in 1992 could occur in economies which may find it difficult to sustain that level of loss. To take just two examples, the concentrations of economic activity and population in both Greater Manila and in the Hong Kong-Shenzhen-Macao conurbation make those areas particularly vulnerable to economic damage if they were struck by typhoons of the highest strength, as nearly occurred when Hong Kong was struck by Typhoon York in September 1999.

City centre buildings in all these areas tend to be tall, and are generally designed to withstand the highest wind likely to be encountered in 50 or 100 years without collapsing. Given the use of safety factors in structural design it is very unusual for such a building to collapse or suffer irremedial structural damage in the highest winds experienced, but the fact remains that serious damage to such buildings does occur in typhoons, and is often apparently caused by windborne debris, either loose material picked up by the wind, or flying debris released by mechanical failure in less well designed structures [1]. The cumulative damage inflicted by the debris, particularly on cladding elements, may lead to serious external damage including breaching of the building envelope. When account is taken of the high rainfall rates associated with typhoon landfall it is easy to see that such a breach of a building envelope would cause significant damage to contents including furniture, electronic equipment and records, which could have a devastating effect on business operations.
Three features of modern city centre environments give particular cause for concern. A large fraction of the newest buildings are of all-glass curtain-wall construction, and many of these buildings are built in areas where considerable amounts of loose debris or poorly-restrained building components or other materials abound that could easily become wind-borne missiles under high wind conditions. Thirdly, the relatively infrequent nature of typhoon strikes in particular locations leads to a false sense of security amongst both city administrators as well as populations at large.

\section{INSURANCE LOSS ESTIMATION}

At present insurance premiums for losses caused by the damage to high rise buildings from typhoon strikes in urban areas are normally based on the use of catastrophe models with three principle component parts, Hazard Evaluation , Vulnerability Estimation and Loss Estimation.

The Hazard Evaluation part of the process is well founded on the use of one of a number of wind field models all of which have their fundamental principles explained in the open scientific literature, reviewed recently in [2]. There is possibly little to choose between the models so far as their description of the mean wind field at gradient height ( the 'gradient wind' ) is concerned. The factors which relate near ground wind gust speeds to the gradient wind are commonly quite empirical and may vary appreciably from model to model. The use of additional factors to modify wind speeds upon tropical cyclone landfall to allow for changes in ground terrain and topography is at best unsophisticated, and indeed omitted from many of the available models, despite the major impact which such factors have in most national wind loading codes [3]. The latter are based on extensive 
research on winds in extra-tropical storms, but much could be translated into tropical cyclone modelling. At present, the sophistication of the numerical and computational modelling in many stages of the analysis is often compromised in the final output by use of factors based on the sparse amount of full scale data on detailed wind structure specifically derived from tropical cylone measurements. The topographic and terrain change factors are likely to have greater impact in many south east asian cities, Hong Kong for example, than in the cities of the US south eastern seaboard, the source of much of the available full scale data.

The Vulnerability Estimation part of the process, unlike Hazard Evaluation, is not grounded on a fundamental theory of physical behaviour. Vulnerability curves are used which normally describe percentage damage to buildings as a function of wind speed and which are parameterised to differing degrees to permit different building types in different types of location to be studied. The data underpinning these loss curves is based on the history of past events at times and in locations wherever damage due to windstorms has occurred. There are three specific drawbacks to this procedure. The first of these is that since the data is historical by definition it will always lag behind changes to the form and structure of the buildings themselves, and cannot reflect changes in architectural style, construction methods or prescriptive building legislation. The second drawback concerns location. Again by definition the dataset can only reflect those locations in which past damage has occurred and must ignore buildings in new regions or those in areas hitherto untouched by wind storms.

The third drawback concerns the wind climate. In order to accumulate sufficient data for statistical reliability in the loss estimation dataset there may be a tendency to incorporate within it information from storms which represent quite different types of wind field. Such a collection might include tropical cyclones, tornados, thunderstorm downdrafts, mountain range lee waves as well as temperate zone cyclonic storms. The consequences of this collection of data sources would be a range of different storm durations, turbulence levels, vertical wind structure and spatial correlations, all of which may influence to damage levels to buildings and structures for a given mean wind speed.

Loss Estimation is the process of converting percentage building damage factors to a monetary value for different building types in different locations and different local economies. Here it is clearly necessary to distinguish between direct and indirect losses, structural and non-structural damage , contents and building damage as well as loss of business opportunity costs. Notwithstanding the complexities herein, it should be the most accurate part of the process.

Potential improvements to the present procedures fall into two groups. The first of these concerns the use of empirical factors to convert the values of the gradient height mean wind field into the maximum gust wind speeds experienced by specific buildings in specific locations. These factors include gradient height to $10 \mathrm{~m}$ reference height ratios, mean to gust speed ratios, building proximity factors and terrain and topography correction factors. It is beyond the scope of the present paper to deal with these matters here, though note must be made of them.

The second area of potential improvement concerns the whole process of vulnerability estimation. It would appear that the loss curves being used at present in most of the available catastrophe models relate to US and Caribbean data for hurricane damage, most of which was to residential buildings. The major hurricane strikes of recent years ( Andrew, Floyd, Fran, Georges, Hugo, Gilbert etc ) have tended to miss significant downtown urban areas and so their contributions to the dataset must necessarily be based on damage to residential areas, with the possible exception of Alicia to Houston centre in 1983. The application of vulnerability curves relating wind speed to percentage damage levels derived in this way are unlikely to yield accurate values for the totally different building populations of south east asian cities. Given the lack of claims data for modern high rise city centres on which to base vulnerability models, an improved methodology must be sought in which an engineering risk analysis is applied to the mechanics of the failure processes.

The remaining sections of this paper explain how a flying debris model has been created which enables the speed at which different types of debris becomes airborne to be calculated and in turn relates this to their damage capability.

\section{DEVELOPMENT OF THE FLYING DEBRIS MODEL}

The model seeks to link the aerodynamics of debris particles with the damage caused when flying debris strikes a building or other structure. The aerodynamic force on such a particle in the direction of the wind vector can be written as 
$\mathrm{F}=1 / 2 \rho_{\mathrm{a}} \mathrm{u}^{2} l^{2} \mathrm{C}_{\mathrm{N}}$

where $\rho_{\mathrm{a}}$ is the air density, $u$ is the relative velocity between the wind and particle, /is a typical dimension of the particle and $C_{N}$ is a force coefficient that is assumed to be constant for the particular orientation of the particle to the wind.

A clear distinction can be drawn between particles lying on the ground and attached particles. Loose materials will start to move under wind action if their wind loading exceeds the product of their weight and a "friction coefficient". A broad distinction between "loose" objects with an effective friction coefficient of about unity, and "fixed" objects where the wind force required to break them loose is greater than their own weight will also be assumed, where the ratio of these forces is defined as $I$, the fixture strength integrity. The conditions for flight will occur when the lift on an object exceeds its weight, that is when

$$
1 / 2 \rho_{\mathrm{a}} \mathrm{u}^{2} l^{2} \mathrm{C}_{\mathrm{L}}>\mathrm{mg}
$$

or since $\mathrm{m}=\rho_{\mathrm{m}} l^{3}$

$$
1 / 2 \rho_{\mathrm{a}} \mathrm{u}^{2} \mathrm{C}_{\mathrm{L}}>\rho_{\mathrm{m}} l \mathrm{~g}
$$

where $\rho_{m}$ is the density of the material. To the level of accuracy of this simple model, there is little distinction between $C_{L}, C_{N}$ and $C_{D}$, and the use of a generalised force coefficient $C_{F}$ is more appropriate. With this simplification the following scenario can be set up: in the steadily increasing wind of a typhoon, very poorly restrained objects with $I<1$ (fixing strength less than their weight) will come loose from their fixings when $1 / 2 \rho_{\mathrm{a}} \mathrm{U}^{2} \mathrm{C}_{\mathrm{F}}>\rho_{\mathrm{m}} \lg I$, but the aerodynamic force will be insufficient for them to "fly", and they will fall to the ground and remain there with $I$ now equal to one until $1 / 2 \rho_{\mathrm{a}} \mathrm{U}^{2} \mathrm{C}_{\mathrm{F}}>\rho_{\mathrm{m}} l \mathrm{~g}$ when they will start to move downwind and become a potential hazard.

Better restrained objects $(I>1)$ will remain attached until

$$
1 / 2 \rho_{\mathrm{a}} \mathrm{U}^{2} \mathrm{C}_{\mathrm{F}}>\rho_{\mathrm{m}} \lg I
$$

They will then also come loose, but since the value of $U$ at which this happens is higher than the minimum required for flight, they will travel further, accelerating towards the wind speed $U$, losing relative speed and perhaps falling to the ground if the initial value of $I$ was not much above one. In this model it will be assumed that missiles reach a proportion $J$ of the wind speed.

Although equation (4) has been written as an inequality, in the steadily increasing wind speed of a typhoon a simple assumption would be that each object flies as soon as condition (4) is reached, so that the condition for flight becomes

$$
1 / 2 \rho_{\mathrm{a}} \mathrm{U}^{2} \mathrm{C}_{\mathrm{F}}=\rho_{\mathrm{m}} \lg I
$$

or

$$
\mathrm{U}^{2}=2\left(\rho_{\mathrm{m}} / \rho_{\mathrm{a}}\right)\left(I / \mathrm{C}_{\mathrm{F}}\right) l \mathrm{~g}
$$

This equation implies that for fixed values of $I$ and $\rho_{\mathrm{m}}$, smaller particles become airborne first, and that as wind speed gradually increases, larger and larger particles become missiles. Also heavier particles, higher $\rho_{m}$, require a higher wind speed in order to become airborne.

To illustrate this, Table 1 shows examples of the sizes of particles of two different materials, wood and stone, that would begin to fly at three different wind speeds.

Table 1. Flight Speeds for Particles

\begin{tabular}{|l|l|l|l|}
\hline $\begin{array}{l}\text { Wind } \\
\text { speed } \\
\mathrm{m} / \mathrm{s}\end{array}$ & Material & $\begin{array}{c}\text { Size } \\
\mathrm{mm}\end{array}$ & $\begin{array}{l}\text { Kinetic Energy } \\
\text { Joules }\end{array}$ \\
\hline 10 & Wood & 12 & 0.05 \\
\hline 10 & Stone & 2 & 0.0017 \\
\hline 20 & Wood & 50 & 12 \\
\hline 20 & Stone & 9 & 0.4 \\
\hline 40 & Wood & 200 & 3200 \\
\hline 40 & Stone & 37 & 110 \\
\hline
\end{tabular}

At $10 \mathrm{~m} / \mathrm{s}$ a piece of wood about $12 \mathrm{~mm}$ in size can be moved by the wind, whereas the same wind speed can move only a $2 \mathrm{~mm}$ piece of stone. Doubling the wind speed increases the size of particle that can be moved by a factor of four, and so on. The last column shows the kinetic energy of such particles and demonstrates how much more dangerous less dense materials are at a given wind speed.

A similar analysis can be performed for sheet materials such as plywood or corrugated iron, typical of material torn from a building in high winds. This time the equation governing the flight criteria becomes

$$
\mathrm{U}^{2}=2\left(\rho_{\mathrm{m}} / \rho_{\mathrm{a}}\right)\left(I / \mathrm{C}_{\mathrm{F}}\right) \operatorname{tg}
$$

Whilst this equation looks similar to its equivalent for solid particles, equation (6) there is a crucial difference. This time the initial flight speed is 
dependant, not on size, but on mass/unit area, the product of density and thickness. Thus the same wind speed would apply equally to a $1 \mathrm{~mm}$ corrugated iron sheet and to a $15 \mathrm{~mm}$ plywood sheet. Making a appropriate assumption for the drag coefficient which takes account of its tumbling motion through the air it is possible to construct a table for flight speeds for sheets.

Table 2. Flight Speeds for Sheets

\begin{tabular}{|l|l|l|l|l|}
\hline $\begin{array}{c}\text { Wind } \\
\text { speed }\end{array}$ & $\begin{array}{l}\text { Limiting } \\
\text { mass/uni } \\
\text { area } \\
\mathrm{kg} / \mathrm{m}^{2}\end{array}$ & \multicolumn{2}{|c|}{$\begin{array}{l}\text { Critical sheet } \\
\text { thickness } \mathrm{mm}\end{array}$} & $\begin{array}{l}\text { Steel Timber } \\
\text { energy/uni } \\
\text { area } \\
\mathrm{J} / \mathrm{m}^{2}\end{array}$ \\
\hline 10 & 1.9 & 0.25 & 3.5 & 95 \\
\hline 20 & 7.5 & 1.0 & 15 & 1500 \\
\hline 40 & 30 & 3.8 & 60 & 24000 \\
\hline
\end{tabular}

Finally, the analysis can be carried out for 1dimensional, rod-like, objects where the examples of bamboo poles are as common in Pacific Rim countries as " $2 \times 4$ " timbers are in North America. The corresponding flight equation for objects defined by a length $l$ and an equivalent diameter $d$ is as follows .

$$
\mathrm{U}^{2}=\pi / 2\left(\rho_{\mathrm{m}} / \rho_{\mathrm{a}}\right)\left(I / \mathrm{C}_{\mathrm{F}}\right) d \mathrm{~g},
$$

This produces a similar equation to that for sheets where now the equivalent diameter takes the place of the thickness. Table 3 gives the initial flight speeds for some common rod like objects.

Table 3. Flight Speeds for Rods

\begin{tabular}{|l|l|c|c|}
\hline Rod type & $\begin{array}{l}\text { Size } \\
\text { Length } \mathrm{x} \\
\text { Diameter } \\
\mathrm{m} \times \mathrm{mm}\end{array}$ & $\begin{array}{l}\text { Initial flight } \\
\text { speed } \\
\mathrm{m} / \mathrm{s}\end{array}$ & $\begin{array}{l}\text { Kinetic } \\
\text { energy } \\
\mathrm{J}\end{array}$ \\
\hline Steel rod & $1.0 \times 1$ & 14 & 0.7 \\
\hline Bamboo & $3.0 \times 30$ & 13 & 50 \\
\hline Bamboo & $3.0 \times 75$ & 22 & 1000 \\
\hline $2 \times 4$ & $2.4 \times 80$ & 32 & 3800 \\
\hline
\end{tabular}

\section{A DAMAGE FUNCTION}

When such a missile strikes a building, damage to the facade may or may not occur. Initially it might be assumed that the amount of damage sustained is proportional to the missile kinetic energy.
An expression for the "damage" caused by a single missile then becomes

$$
D=1 / 2 \rho_{\mathrm{m}} l^{3} \mathrm{u}^{2}=1 / 2 \rho_{\mathrm{m}} l^{3} J^{2} \mathrm{U}^{2}
$$

It is now possible to combine this with the flight condition for a solid three dimensional object (5) and eliminate the typical missile dimension /. The damage function then becomes

$$
D={ }^{1} / 16 . \rho_{\mathrm{m}}\left\{\left(C_{F} \rho_{\mathrm{a}}\right) /\left(\rho_{m} I g\right)\right\}^{3} J^{2} \mathrm{U}^{8}
$$

Because of the composition of the flight condition equations (7) and (8) and their different dependence on $U$ for the sheets and rod missile types compared with the solid objects, the damage function becomes a function of only $U^{4}$ in these cases. It is instructive to examine some typical cases to see the implications of equation (10). Table 1 gives the values of the damage function for solid objects. At wind speeds of only 10 $\mathrm{m} / \mathrm{s}$ the wooden missile will create "damage" of $0.05 \mathrm{~J}$, the stone $0.0017 \mathrm{~J}$. These levels of "damage" are probably below the threshold of real damage, though at higher speeds real damage becomes possible for solid objects as well as for sheets and rods, Tables 2 and 3.

\section{CONCLUSIONS}

By examining how insurance industry catastrophe loss models work it has become apparent that there is a need to improve vulnerability loss modelling beyond historical damage statistics. There is a need for a process of engineering risk assessment to be carried out in order to explain how damage failure mechanisms accumulate in wind storm events.

This process of engineering risk assessment for damage estimation in typhoon wind speeds has been initiated with the study of the damage potential due to flying debris explained in this paper.

\section{References}

[1]. Lee B.E. (1988) Engineering Design for Extreme Winds in Hong Kong. Hong Kong Engineer, Vol 16, No.4, pp 15-23.

[2]. Wills J.A.B., Lee B.E. and Wyatt T.A. (2000) A Review of Tropical Cyclone Wind Field Models. Wind and Structures, Vol 3, No. 2, pp 133-142.

[3]. British Standards Institute. ( 1997) Code of Practice for Wind Loads, BS 6399, Part 2.

Key words : typhoon, tropical cyclone, wind damage, flying debris, insurance costs. 


\title{
The mechanics of flying debris and test criteria
}

\author{
J. D. Holmes ${ }^{1}$, P.J .Mullins ${ }^{2}$ \\ 1) JDH Consulting, P.O. Box 269, Mentone, Victoria, 3194, Australia \\ 2) Mullins Consulting, P.O. Box 91, Indooroopilly, Queensland, 4068, Australia
}

\section{INTRODUCTION}

The Shelter Building Program of the Department of Public Works of the state of Queensland, Australia is intended to identify and upgrade existing buildings in the tropical cyclone belt to provide shelter during the event of a severe tropical cyclone. Resistance to flying debris is an important consideration during severe cyclones. Penetration of the building envelope by flying missiles has a number of undesirable results : high internal pressures threatening the building structure, wind and rain penetration of the inside of the building, the generation of additional flying debris, and the possibility of flying missiles inside the building endangering the occupants.

This paper addresses the mechanics of flying debris and describes test criteria developed. Work in the U.K. on the initiation of missile flight is reviewed. A new analysis of flight times and distance travelled is given. The test criteria for missiles proposed and accepted for the Queensland Shelter Building Program are described. Finally the design of a protective missile screen produced by an industrial group in Australia is described briefly.

\section{INITIATION OF MISSILE FLIGHT}

Wills et al (1998), have provided a useful analysis of conditions for the initiation of missile flight during a wind storm. They considered 'compact' objects, sheet objects, and rods and poles, and established relationships between the body dimensions, and the wind speed, $U_{f}$, at which flight occurs and the objects become missiles. For each the three categories, these relationships are :

$$
\ell=\frac{\frac{1}{2} \rho_{\mathrm{a}} \mathrm{U}_{\mathrm{f}}^{2} \mathrm{C}_{\mathrm{F}}}{I \rho_{\mathrm{m}} \mathrm{g}}
$$

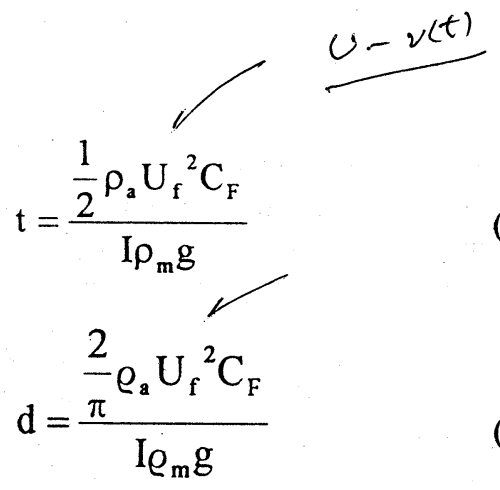

where,

$\ell$ is a characteristic dimension for 'compact' objects

$t$ is the thickness of sheet objects

$d$ is the effective diameter of rod-type objects

$\rho_{a}$ is the density of air

$\mathrm{C}_{\mathrm{F}}$ is an aerodynamic force coefficient

$\rho_{m}$ is the density of the missile material

$\mathrm{U}_{\mathrm{f}}$ is the wind speed at which flight occurs

I is a fixing strength integrity parameter, i.e. the value of force required to dislodge the objects expressed as a multiple of their weight (for objects resting on the ground $I \cong 1$ )

$\mathrm{g}$ is the gravitational constant

Equations (1), (2) and (3) illustrate the important point that the larger the value of the characteristic dimension, $\ell, \mathrm{t}$ or $\mathrm{d}$, the higher the wind speed at which flight occurs. These equations also show that the higher the value of the density, $\rho_{\mathrm{m}}$, the higher is the wind speed for lift off. Thus as the wind speed in a cyclone, or typhoon, builds up, the smaller lighter, objects e.g. gravel, small loose objects in gardens and backyards, 'fly' first. At higher wind speeds appurtenances on buildings are dislodged as the wind forces exceed their fixing resistance, and they also commence flight. At even higher wind speeds, substantial pieces of 
building structure, such as roof sheeting and purlins, may be removed, and become airborne.

\section{FLIGHT TIMES AND DISTANCES}

A missile, once airborne, will continue to accelerate until its flight speed approaches the wind speed, or until its flight is terminated by impact with the ground or with an object such as a building.

The aerodynamic force on a flying object in a wind of speed, $U$, can be expressed as :

Accelerating force $=\frac{1}{2} \varrho_{a}\left(U-v_{m}\right)^{2} C_{D} A$

where $v_{m}$ is the velocity of the missile with respect to the ground, and $\mathrm{A}$ is the reference area for the drag coefficient, $C_{D}$

Applying Newton's law, the instantaneous acceleration of a compact object (characteristic dimension, $\ell$ ), is given by :

Acceleration $=$

$$
\frac{\frac{1}{2} \rho_{\mathrm{a}}\left(U-\mathrm{v}_{\mathrm{m}}\right)^{2} \mathrm{C}_{\mathrm{D}} \mathrm{A}}{\rho_{\mathrm{m}} \ell^{3}}=\frac{\frac{1}{2} \rho_{\mathrm{a}}\left(U-\mathrm{v}_{\mathrm{m}}\right)^{2} \mathrm{C}_{\mathrm{D}}}{\rho_{\mathrm{m}} \ell}
$$

taking A equal to $\ell^{2}$.

The same equation applies to 'rod' type objects when $\ell$ is taken as the length (A is the crosssection area).

Equation (4) shows that heavier and larger objects have lower accelerations, and hence their flight speeds are likely to be lower than smaller or lighter objects. The equation also shows that the initial acceleration from rest $\left(v_{m}=0\right)$ is high, but the acceleration rapidly reduces as the difference between the missile speed and the wind speed reduces, so that the wind speed is approached very slowly. Of course the missile speed cannot exceed the wind speed.

Equation (4) can be integrated to obtain the time taken to accelerate to a given speed, $v_{m}$, and the distance travelled in this time. These equations are as follows :

Time taken to accelerate from 0 to $v_{m}$,

$$
\mathrm{T}=\frac{\mathrm{v}_{\mathrm{m}}}{\mathrm{kU}\left(\mathrm{U}-\mathrm{v}_{\mathrm{m}}\right)}
$$

Distance travelled,

$$
\mathrm{s}=\mathrm{U}\left[\mathrm{T}-\left(\frac{1}{\mathrm{kU}}\right) \ln (1+\mathrm{kUT})\right]
$$

where $k=\left(\rho_{a} C_{D}\right) /\left(2 \rho_{m} \ell\right)$ with units of $(1 / m)$.

Using Equations (5) and (6), the flight times and distance travelled by a) a steel ball of $8 \mathrm{~mm}$ diameter and 2 gram mass, and b) a $4 \mathrm{Kg}$ piece of timber of $100 \mathrm{~mm}$ by $50 \mathrm{~mm}$ cross section, and length 1.6 metres, have been calculated, for a wind speed, $U$, of $32 \mathrm{~m} / \mathrm{s}$ (a reasonable value of mean wind speed for a design cyclone in an urban area on the Queensland coast), and are given in Table I.

Table I shows the much longer flight times and distances for the larger object.

\section{MISSILE TEST CRITERIA}

When specifying appropriate test criteria for missile impact resistance, the following principles should be followed :

- The missiles should be representative of actual objects available.

- The criteria should be physically realistic, i.e. if the flight threshold speed is greater than the expected wind speed in the storm, then the object should not be regarded as a potential missile.

- Unrealistic flight times and distances should not be implied by the specified missile speed.

The first missile testing criteria in Australia was included in the Darwin Area Building Manual (Darwin Reconstruction Commission, 1976), following Cyclone 'Tracy' in 1974. This test specified that windows and doors should withstand impact at any angle of a piece of $100 \mathrm{~mm}$ by $50 \mathrm{~mm}$ timber weighing 4 Kilograms, travelling at $20 \mathrm{~m} / \mathrm{s}$. A more severe test was specified for cyclone refuge shelters: 'end-on' impact of a piece of $100 \mathrm{~mm}$ by $50 \mathrm{~mm}$ timber weighing $8 \mathrm{Kilograms}$, travelling at $30 \mathrm{~m} / \mathrm{s}$. As shown in Table $I$, to reach $30 \mathrm{~m} / \mathrm{s}$, a $4 \mathrm{Kg}$ timber missile would need to travel for more than 10 minutes, and over 16 kilometres. Shortly after Cyclone 'Tracy' a larger $(8 \mathrm{Kg})$ timber missile travelling at $30 \mathrm{~m} / \mathrm{s}$ was originally specified for cyclone refuge shelters in Darwin. Fortunately 
such an unrealistic specification was dropped a year or two later.

Following a meeting of experts held at the Experimental Building Station, Sydney, in 1977, Technical Record 440 (Experimental Building Station, 1978) was issued. This reduced the test requirement for windows and doors of buildings to a piece of $100 \mathrm{~mm}$ by $50 \mathrm{~mm}$ timber weighing 4 $\mathrm{Kg}$, travelling at $15 \mathrm{~m} / \mathrm{s}$. This test has since been adopted by the Darwin Area Building Code, and is also mentioned in the Australian Standard on Wind loads AS1170.2-1989 (Standards Australia, 1989), in relation to the prevention of dominant openings and resulting high internal pressures in cyclonic regions.

Following the above principles, the following procedures for the testing of debris screens and cladding for public shelter buildings in the Queensland coastal region (corresponding to Region C in AS1170.2), were proposed.

\section{Debris Test Load A}

End-on impact of a piece of timber 4 kilograms in mass, with cross-section dimensions of $100 \mathrm{~mm}$ by $50 \mathrm{~mm}$ impacting at $20 \mathrm{~m} / \mathrm{s}$

\section{Debris Test load B}

Series of five steel balls of 2 grams mass $18 \mathrm{~mm}$ diameter) impacting at $30 \mathrm{~m} / \mathrm{s}$ successively

The first of these missiles is representative of a roof purlin and has previously been used in Australia as a test missile, as discussed earlier. The steel balls are representative of small hard compact objects, and have previously been adopted as test missiles for the hurricane-prone regions of Florida (Pantelides et al, 1992). The test specifications require these missiles to be projected at both 90 degrees and 30 degrees to the plane of the screen.

Both of these missile types have a flight threshold speed (estimated from the Equations (1) and (3)) about equal to the mean wind speed at the peak of the design ultimate cyclone. AS 1170.2 gives this speed as $28-33 \mathrm{~m} / \mathrm{s}$ in urban terrain, for heights up to 10 metres. Note that the gust speed is approximately twice the mean wind speed (i.e. $55-60 \mathrm{~m} / \mathrm{s}$ in urban areas in the design event).

The missiles will have accelerated to about $95 \%$, and $65 \%$ of the mean wind speed, for cases $A$ and $B$ respectively, at the peak of the design storm. Application of Equations (5) and (6) indicates that the missiles will have taken about 50 and 70 seconds of flight time, respectively, and travelled nearly a kilometre to reach these speeds. At the specified speeds, impacts by these missiles are clearly extreme events, but are considered comparable with the risk of the building receiving the extreme (ultimate limit states) wind load specified by the wind loads Standard (Standards Australia, 1989).

\section{PROTECTIVE MISSILE SCREEN}

The Shelter Program of the Department of Public Works of the Queensland Government has adopted the criteria, test procedures and specifications described in the previous section. The program is intended to identify and upgrade existing buildings in the region of Queensland affected by tropical cyclones, for use as public shelters during the event of a severe storm. It is not possible for many normal cladding materials, such as glazing, to resist the missiles as specified. A solution to this is to provide protective missile screens, which may be permanently in place, or are installed in the event of a storm warning.

The screen material may vary depending on the building owner's requirements. A louvre-type mesh can be used to provide protection from solar radiation, or a finer mesh used where see-through vision is required. To be able to resist the steel ball impacts (Debris Test Load B), the largest aperture in the screen should not exceed $8 \mathrm{~mm}$. To ensure that the glazing, or other cladding, is not failed by the screen deflecting following the missile impact, the screen should be located at a distance of at least 1.25 times the maximum displacement under the impact test. The screen should envelop the glazed panel. This can be achieved by returning to the wall to completely envelope the opening, or overlapping the opening in the plane parallel to the wall.

BHP Building Products has constructed a test facility to project the missiles, and have developed Stormgard Cyclonic Debris Screens to meet the shelter requirements (Figure 1). The energy absorbing element of the screens consist of expanded steel mesh material. Two types of screen were used, and both were found to be capable of meeting the missile impact requirements.

\section{CONCLUSIONS}

A missile test protocol has been specified to satisfy the strict requirements of the Queensland Shelter Building Program for the coastal strip affected by tropical cyclones. After an analysis of the mechanics of flying debris, two missile 
types have been specified and accepted, with realistic speeds in relation to the wind speeds expected in the most severe storms affecting the region.

\section{REFERENCES}

Darwin Reconstruction Commission. Darwin Area Building Manual (1976).

Experimental Building Station. Guidelines for evaluation of products for cyclone-prone areas. Technical Record 440. E.B.S. Sydney, (1978).

C.P. Pantelides, A.D. Horst, and J.E. Minor, Post-breakage behaviour of architectural glazing in wind storms. Journal of Wind Engineering and Industrial Aerodynamics, Vol. 41-44, pp24252435, 1992.
Standards Australia. S.A.A. Loading Code, Part 2, Wind loads. AS1170.2-1989.

J. Wills, T.A.Wyatt, and B.E. Lee. Warnings of high winds in densely populated areas. United Kingdom National Coordination Committee for the International Decade for Natural Disaster Reduction, 1998.

Key words : Cyclone, debris, missile, typhoon, wind loads

\section{ACKNOWLEDGEMENTS}

The support of the Queensland Department of Works for the study described, is gratefully acknowledged by the authors. The assistance of Cam Seccombe (BHP) in providing a photograph of the 'Stormgard' screen is also acknowledged.

Table I Flight times and distances for some missiles (wind speed $=32 \mathrm{~m} / \mathrm{s}$ )

\begin{tabular}{|c|c|c|}
\hline Object / speed & Time taken (secs) & $\begin{array}{c}\text { Distance travelled } \\
\text { (metres) }\end{array}$ \\
\hline Steel ball to $20 \mathrm{~m} / \mathrm{s}$ & 5.4 & 71 \\
\hline Steel ball to $30 \mathrm{~m} / \mathrm{s}$ & 49 & 1270 \\
\hline Timber piece to $20 \mathrm{~m} / \mathrm{s}$ & 69 & 910 \\
\hline Timber piece to $30 \mathrm{~m} / \mathrm{s}$ & 625 & 16300 \\
\hline
\end{tabular}

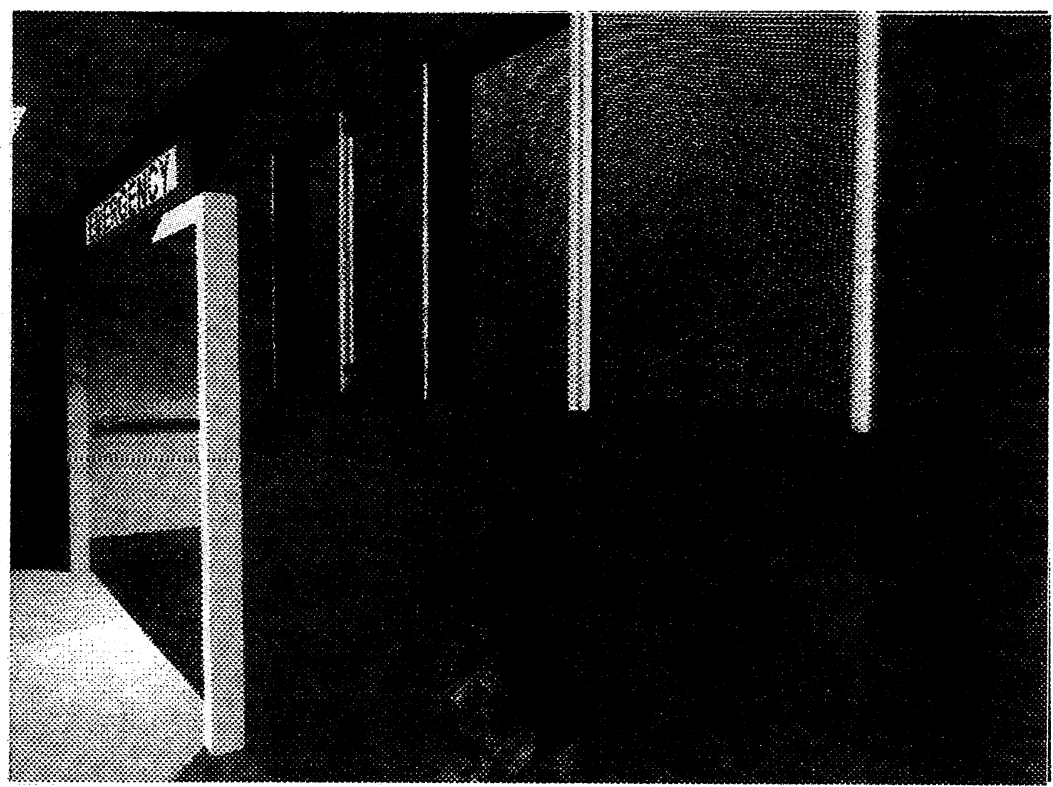

Figure 1. Installation of a Stormgard missile protection screen 


\title{
INDIAN EFFORTS TOWARDS WIND RESISTANT HOUSING
}

\author{
Prem Krishna \\ Professor of Bridge Engineering, Railway Chair, Department of Civil Engineering, \\ University of Roorkee, ROORKEE - 247667, INDIA
}

\section{INTRODUCTION}

The last few decades of the twentieth century have been characterised by an increasing trend of natural catastrophes of different kind. A compilation of such events by the Munich Reinsurance company in Germany upto the year 2000 indicates this increasing trend as shown in Table 1 .

The reasons for this obviously increasing. trend are perhaps the following:

1. Rise in population

2. Concentration of people in affected regions

3. Industrialisation in affected regions

4. Changes in Environmental conditions

5. Better standards of living

Data from the same source indicates the proportion of losses in natural disasters on a regional basis (Asia-Pacific) and on the basis of the type of disaster, also for the Asia-Pacific. This is given in Tables 2 and 3.

It is obvious that the Asia-pacific region is badly effected. India - a large country, which is part of the region, suffers mainly three types of hazards wind storms, earthquakes and floods. Data analysis for India shows wind to be one of the worst killers. One of primary factors which leads to loss of human life, disruption of the social fabric and misery is the damage or destruction of housing. Whereas several other factors contribute to economic losses, the loss of housing is a major cause of the human aspect of the tragedy. Therefore in different stages of disaster management, whether this be preventive actions, relief, or rehabilitation, housing has to be kept in focus.
India has suffered several major wind storm disasters in the last 25 years - the Andhra Cyclones in 1977 and 1990, the Gujrat Cyclone in 1998 and the Orissa 'super' cyclone in 1999. Each time there has been a heavy toll of economic and human losses. In addition to tightening up the measures to forecast cyclones, to provide relief and to rehabilitate, there has been a major thrust on developing the preventive measures. This includes the effort towards the provision of cyclone - resistant housing. In the context of the cyclone - affected regions of the country, this is a gigantic task, judged from the figures on housing.

There are an estimated 235 million housing units in the country (extrapolated from the 1991 census) and the level of risk these run from wind storms is,

$$
\begin{array}{ll}
\text { High - Very high } & 78 \text { million } \\
\text { Moderate } & 57 \text { million } \\
\text { Low-Very low } & 100 \text { million }
\end{array}
$$

These are macro - level figures. However it is adequately clear from the data that whereas there is a need to develop measures for cyclone - resistant construction and to introduce them in providing new housing units (this is indeed being done) there is a need to look at the existing housing too. The action needed thus breaks down into several steps. There is a need to,

i. make macro level assessments (such as the one above) and to develop disaster scenarios to help in planning disaster mitigation measures,

ii. carryout surveys of housing to establish their typology of construction, and to classify these according to structural features, 
iii. carryout damage surveys to make a damage grading and to determine damage patterns,

iv. design retrofit and other counter measures based on (ii) and (iii) above,

v. introduce techno - legal regimes to ensure that various measures become applicable,

vi. continue to carryout research to produce improved information for the analysis and design of housing structures.

\section{VULNERABILITY ATLAS OF INDIA}

Preparation of the vulnerability atlas published ${ }^{(1)}$ in 1997 has been the backbone of efforts that have followed in relation to providing disaster resistant housing. The atlas contains invaluable data on three hazards most common to India, namely, wind storms, earthquakes and floods. The atlas provides state-wise maps for the three hazards. In addition the atlas provides risk tables for houses for the 400 plus districts into which the country is divided. The total available housing is given as per its typology vis-à-vis materials and type of roofing and its level of risk to hazards has been assessed in qualitative terms. Table 4 is a typical extract from such a table in the atlas.

The atlas has two compendium volumes, one containing "Techno-legal aspects and land use zoning" and the other containing "Guidelines for improving hazard resistant construction of buildings". All in all the atlas provides invaluable data for planners, designers and constructors alike for planning and constructing new houses as well as to strengthen and retrofit existing ones. A unique feature of the atlas is a section consisting of a methodology for predicting disaster scenarios.

\section{CYCLONE DISASTER SCENARIO} disaster,

The model includes two aspects of the

i. Number of houses expected to be damaged or destroyed.

ii. Number of fatalities expected.

The number of houses destroyed or damaged in an effected district area can be predicted by using the following relation:

$$
H=\sum_{i=1}^{m} \sum_{j=1}^{8} H_{j} \alpha_{i} r_{i j} P_{j}, \text { where }
$$

$\mathrm{H}_{j} \quad$ is number of houses of type $\mathrm{j}$ in the district,

$\alpha_{i} \quad$ is the unit fraction of the district area,

$r_{i j}$ is the damage risk coefficient for the house type and risk level of the area,

$\mathrm{p}_{\mathrm{j}} \quad$ is the premium for the construction type, and,

$\mathrm{m}$ is the number of different level of risk in the district.

By training the model on available data, the risk coefficients $r$ have been obtained and are given in Table 5

A premium, $\mathrm{p}$, has been used for better quality construction which is expected to be engineered. For example, the factor used for R.C. construction is 0.25 and for brick construction it is 0.5 .

Likewise to asses human casualties the following expression has been set up

$$
\begin{array}{ll}
\mathrm{Hc}=\sum_{i=1}^{\mathrm{m}} \mathrm{p} \mathrm{c} \alpha_{i} \mathrm{r}_{\mathrm{i}} \\
\mathrm{Hc} & \text { Number of Human Casualties. } \\
\mathrm{p} & \text { Population of the sample area. } \\
\alpha_{i} & \text { Area Fraction Related to a given } \\
& \text { Hazard or Risk Level } \\
\mathrm{r}_{\mathrm{i}} & \text { The Risk Coefficient for the Hazard } \\
& \text { Level. } \\
\text { c } & \text { Non compliance factor. }
\end{array}
$$

The warning non-compliance factor has been taken as a function of preparedness which improves with time and the risk coefficients depend upon the vulnerability. For example the values taken in a study are as follows:

\begin{tabular}{ccc} 
Year & \multicolumn{2}{c}{$\begin{array}{l}\text { Warning non-complian } \\
\text { factor }\end{array}$} \\
1977 & & 0.100 \\
1990 & & 0.007 \\
1997 & & 0.004 \\
2007 & & 0.001
\end{tabular}
Table 6.

Likewise, the risk factor used is given in

The model is very simple and can be made more elaborate, though the real issue is to continue to improve upon the various factors used by training them on available data. One possible way to finetune the procedure is by way of pre - and post disaster surveys. 


\section{SURVEYS}

Recent surveys of damage following the 1998 Gujarat cyclone and the 1999 Orrisa cyclone and processing of obtained data provide invaluable information. Information from such surveys which includes photographic records of damage, can be used for designing retrofit, repair or reconstruction measures. A similar exercise has been carried out as part of an ongoing project at the University of Roorkee ${ }^{(2)}$.

\section{CONCLUDING REMARKS}

On the basis of exercises and studies, which have led to the above mentioned wind disaster mitigation effort with particular reference to housing in the coastal regions of India, effective steps have been, or are being taken. The technical back-up is adequate, while studies such as ref.2. are providing 'on ground' micro level information.

The areas of concern are the implementation and the financial aspects of a necessarily voluminous task. Progress is taking place on both these counts, though slowly.

\section{References}

1). "Vulnerability Atlas of India", Building Material Technology and Promotion Council, Ministry of Urban Affairs and Employment, Govt. of India, New Delhi, 1997.

2) Korikana Srinu Babu, "Computer Aided Retrofitting for houses in Cyclones Effected Regions", Master's Dissertation, Department of Civil Engineering, University of Roorkee, Roorkee, India, 2001. 
Table 1: Comparison of Great naturat Disasters decade - wise

\begin{tabular}{|l|c|c|c|c|}
\hline Decade & $1960 \mathrm{~s}$ & $1970 \mathrm{~s}$ & $1980 \mathrm{~s}$ & $1990 \mathrm{~s}$ \\
\hline Numbers & 27 & 47 & 63 & 84 \\
\hline Economic losses (US S billion) & 73.1 & 131.5 & 204.2 & 591 \\
\hline
\end{tabular}

Table 2: Disaster Losses 1985 - 2000

\begin{tabular}{|l|c|c|c|}
\hline & Worldwide & Asia-Pacific & Percentage \\
\hline Lives Lost & 536,250 & 443,480 & 82.7 \\
\hline Economic Losses (US S million) & 895,800 & 426,270 & 47.5 \\
\hline
\end{tabular}

Table 3: Losses in the Asia-Pacific due to Wind Storms Vs Total, 1985-2000

\begin{tabular}{|l|c|c|c|}
\hline & $\begin{array}{c}\text { Total } \\
\text { (for all natural disasters) }\end{array}$ & $\begin{array}{c}\text { Due to } \\
\text { Wind }\end{array}$ & Percentage \\
\hline Lives Lost & 443,480 & 60,250 & $14.0^{\circ}$ \\
\hline Economic Losses (US S million) & 426,270 & 62,120 & $14.6^{\circ}$ \\
\hline
\end{tabular}

* This percentage is very much higher for North America

Table 4: Distribution of Houses by Predominant Materials of Wall and Roof and level of Damage Risk - Extract from a typical table in the Vulnerability Atlas

\begin{tabular}{|c|c|c|c|c|c|c|c|}
\hline \multicolumn{2}{|c|}{ Wall and Roof Combination } & \multicolumn{2}{|c|}{ Census Houses } & \multicolumn{4}{|c|}{ Level of Risk under Wind Velocity $\mathrm{m} / \mathrm{s}$} \\
\hline & & \multirow{3}{*}{$\begin{array}{l}\text { No. of } \\
\text { Houses }\end{array}$} & \multirow[t]{3}{*}{$\%$} & \multirow{2}{*}{\multicolumn{4}{|c|}{$\begin{array}{c}47 \\
\text { Area in } \%\end{array}$}} \\
\hline & & & & & & & \\
\hline & & & & 5.0 & 40.2 & 48.0 & 6.8 \\
\hline \multirow[t]{2}{*}{$\begin{array}{l}\text { CATEGORY - A } \\
\text { Al Mud Wall } \\
\text { All Roofs sloping }\end{array}$} & $\begin{array}{l}\text { Urban } \\
\text { Rural }\end{array}$ & $\begin{array}{r}5,422,316 \\
57,104,950 \\
\end{array}$ & $\begin{array}{r}2.78 \\
29.28\end{array}$ & & & & \\
\hline & Total & $62,527,266$ & 32.06 & VH & $\mathbf{H}$ & $\mathbf{M}$ & $\mathbf{L}^{*}$ \\
\hline \multirow[t]{2}{*}{$\begin{array}{l}\text { A2 Unburned Brick } \\
\text { Wall } \\
\text { (a) Sloping roof }\end{array}$} & $\begin{array}{l}\text { Urban } \\
\text { Rural } \\
\end{array}$ & $\begin{array}{l}1,937,714 \\
9,951,794 \\
\end{array}$ & $\begin{array}{l}0.99 \\
5.10 \\
\end{array}$ & & & & \\
\hline & Total & $11,889,508$ & 6.10 & VH & $\mathbf{H}$ & $\mathbf{M}$ & $\mathbf{L}$ \\
\hline \multirow[t]{2}{*}{ (b) Flat roof } & $\begin{array}{l}\text { Urban } \\
\text { Rural }\end{array}$ & $\begin{array}{l}119,042 \\
161,492 \\
\end{array}$ & $\begin{array}{l}0.06 \\
0.08\end{array}$ & & & & \\
\hline & Total & 280,534 & 0.14 & VH & H & $\mathbf{M}$ & $\mathbf{L}$ \\
\hline \multirow[t]{2}{*}{$\begin{array}{l}\text { A3 Stone Wall } \\
\text { (a) Sloping roof }\end{array}$} & $\begin{array}{l}\text { Urban } \\
\text { Rural }\end{array}$ & $\begin{array}{r}2,111,574 \\
12,445,497 \\
\end{array}$ & $\begin{array}{l}1.08 \\
6.38 \\
\end{array}$ & & & & \\
\hline & Total & $14,557,071$ & 7.46 & VH & $\mathbf{H}$ & $\mathbf{M}$ & $\mathbf{L}$ \\
\hline \multirow[t]{2}{*}{ (b) Flat roof } & $\begin{array}{l}\text { Urban } \\
\text { Rural }\end{array}$ & $\begin{array}{l}2,308,017 \\
4,838,903 \\
\end{array}$ & \begin{tabular}{ll|}
1.18 \\
2.48 \\
\end{tabular} & & & & \\
\hline & Total & $7,146,920$ & 3.66 & $\mathbf{H}$ & $\mathbf{M}$ & $\mathbf{L}$ & $\mathbf{L}$ \\
\hline Total - Category -A & & $96,401,299$ & 49.43 & & & & \\
\hline
\end{tabular}

* Risk level: $V H$ is very high, $H$ is high; $M$ is moderate and $L$ is low

Table 5: Risk Coefficients for Assessing Housing Damage

\begin{tabular}{|l|c|c|c|c|c|}
\hline Damage Vulnerability & VH & H & M & L & VL \\
\hline Risk Coefficient, $r$ & 0.60 & 0.27 & 0.08 & 0.02 & Zero \\
\hline
\end{tabular}

Table 6: Risk Coefficients for Assessing Human Casualties

\begin{tabular}{|l|c|c|c|c|c|}
\hline Risk Level & $\mathrm{VH}+$ Surge & $\mathrm{VH}$ & $\mathrm{H}$ & $\mathrm{M}$ & $\mathrm{L}$ \\
\hline Risk Coefficient & $5 \times 10^{-2}$ & $5 \times 10^{-3}$ & $5 \times 10^{-5}$ & $5 \times 10^{-8}$ & Zero \\
\hline
\end{tabular}




\title{
Wind-induced Building Damage and Activities for its Mitigation in Japan
}

\author{
Yasushi Uematsu \\ Department of Architecture and Building Science, Tohoku University, Sendai 980-8579, Japan
}

\section{INTRODUCTION}

The Japanese Islands are struck by typhoons almost every year. Besides typhoons, extratropical cyclones, Tatsumaki (spouts) and others cause strong winds. The winds seldom induce such catastrophic disasters that a strong earthquake does. However, since the stricken area is generally wide, the total economic loss in the area may become considerable.

Lessons Iearned from disasters can greatly contribute to the countermeasures against future natural calamities. In particular, it is very important to understand the characteristics and causes of the damage through the post-disaster field investigations. The damage investigations should be made systematically and efficiently. Furthermore, the data and information gained from various fields and areas should be shared freely throughout the world.

On the basis of this understanding, the 'Research Committee on Wind-induced Disasters ( $R C W D$, Chairman: Prof. T. Ohkuma)', JAWE, was organized in 1998 in order to organically cope with the many problems related to wind-induced disasters ${ }^{1)}$. The present paper describes the characteristics of the wind-induced damage to buildings in Japan and outlines the activities of $R C W D$.

\section{CHARACTERISTICS OF WIND DAMAGE TO BUILDINGS}

Fig. 1 shows yearly variation of the number of houses that suffered total collapse or major damage from meteorological disasters in Japan since 1930. It is clear that typhoon is the main cause of the disasters. Note that 'Typhoon' includes the collapse and damage caused by strong winds as well as by floods due to typhoon.

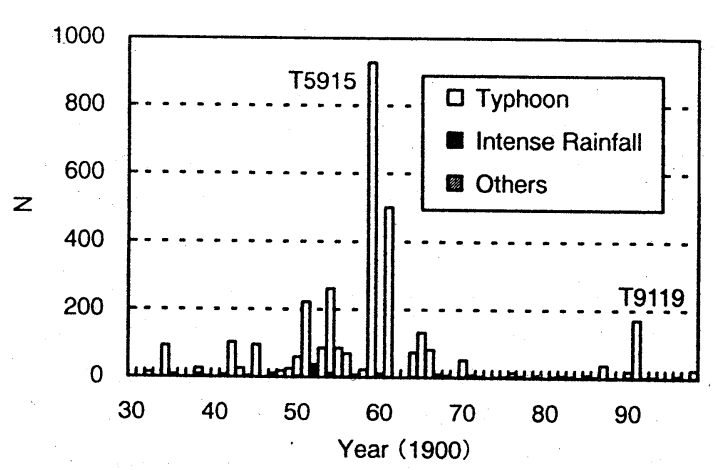

Fig.1 Number $(N)$ of houses that suffered collapse and major damage from meteorological disasters ${ }^{2}$.

Shown in Fig. 2 is the relationship between the rate of total collapse of houses and the maximum instantaneous wind speed (maximum peak gust) for seven severe typhoons in Japan ${ }^{3)}$; the rate is defined as the ratio of the number of collapsed houses to that of households in each municipality. In the figure, ' $X$ ' denotes the results for Typhoon 5915 (the 15th typhoon in 1959, or 'Isewan Typhoon'), and ' $O$ ' the results for Typhoon 9119, which caused the most severe damage in the last four decades. Ishizaki et al. ${ }^{4)}$ indicated that the total collapse rate was roughly proportional to the maximum instantaneous wind speed to the fifth power, as indicated by the solid line in Fig. 2. However, this rate is fairly low for Typhoon 9119; that is, the values are smaller than one tenth of the corresponding values for Typhoon 5915. Such a damage reduction may be related to an improvement of the earthquake resistance of houses; the earthquake resistance is the major concern in the structural design in Japan and a number of studies on this subject have been made, the results of which have been applied to the structural design and construction of buildings. 


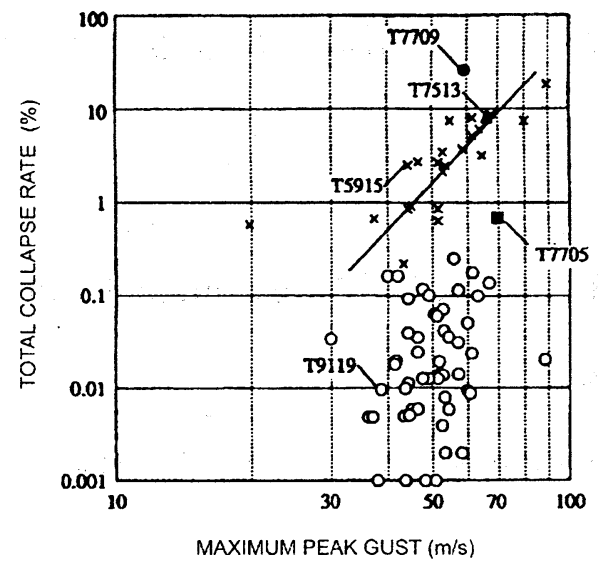

Fig. 2 Relationship between total collapse rate of houses and the maximum peak gust ${ }^{3}$.

Despite the fact that the total collapse rate has decreased recently, significant damage does occur to the envelops of buildings. As mentioned above, the total economic loss will become considerable, even if the damage to each building is not severe. For example, approximately 98 percent of the damaged buildings suffered lightly during Typhoon 9119. However, the insurance money paid for the loss caused by this typhoon reached approximately 570 billion yen, which was at that time the largest amount in the world paid for loss caused by a natural disaster ${ }^{5}$.

The building components tore by strong winds become flying debris and cause damage to the envelopes of other buildings; windows are damaged by such debris in many cases. Breakage of windows not only causes damage to the property inside the building, but also induces the total roof lift-off in some cases.

After the disaster caused by. Typhoon 9119 , we investigated the building damage in Tohoku District (northern district of the Main Island of Japan), which was subjected to severe damage to buildings and crops ${ }^{6) .7)}$. Fig. 3 shows sample results on the damage to houses in Honjo City, Akita Prefecture. The city is divided into seven regions (A to $G$ ) and the damage rates of building components for each region are illustrated in the figure. Fig. 4 shows a comparison for damaged roof area between metal sheet roofing and clay tile roofing, expressed as histogram. The results for the other cities were similar to those presented here. From these figures, the following general features may be detected:

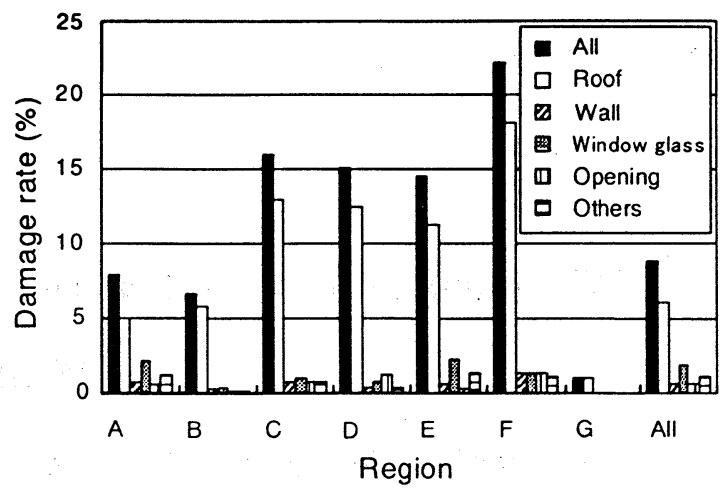

Fig. 3 Damage to houses in Honjo City, Akita Prefecture (see Fig. 6), caused by Typhoon $9119^{6)}$.

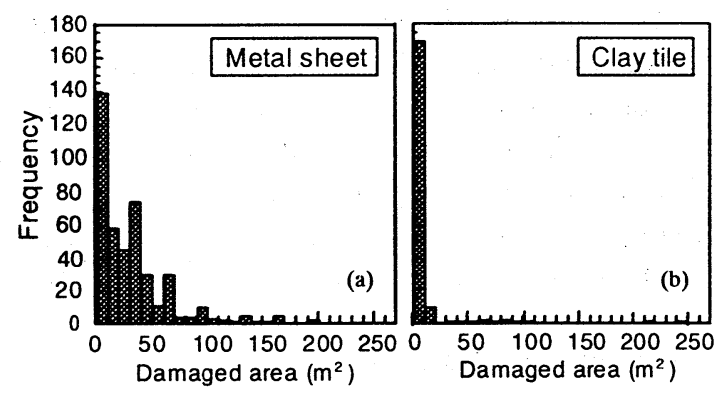

Fig. 4 Damaged roof area for clay tile roofing and metal sheet roofing (Typhoon 9119 , Honjo City) ${ }^{7}$.

(1) Roof is the most vulnerable to wind damage among the building components. The damaged area for metal sheet roofing is much wider than that for clay tile roofing. This feature is related to the tributary area of roofing elements as well as to the method of construction.

(2) The damage rate is strongly dependent on the region. This feature is related to the local topography and the terrain roughness.

(3) The damage rate of window is higher in more densely built-up regions, such as Region $\mathrm{A}$. This feature implies that the breakage of windows is mainly caused by flying debris.

The breaching of building envelope results in the rain entering the building, which causes additional damage not only to the building itself but also to the properties inside the building. As Sparks et al. ${ }^{8)}$ pointed out, such damage may cause the economic loss to be magnified, by a factor of more than two. This damage magnification becomes more important for modern buildings, which are equipped with many kinds of electric facilities. 


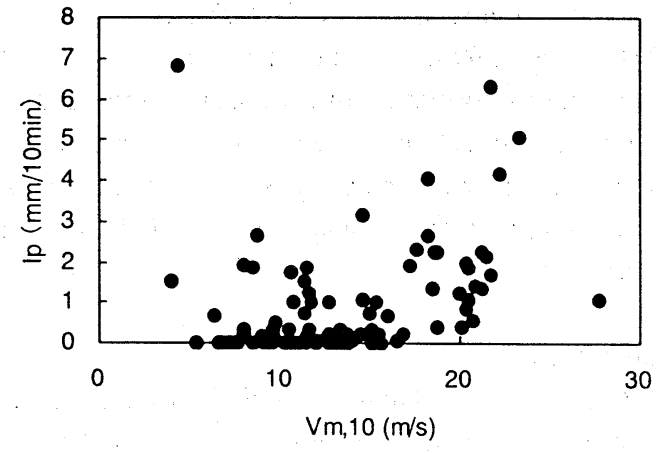

Fig. 5 Relationship between rainfall rate $I_{p}$ and the maximum $10-$ min wind speed $V_{m}, 10 \quad$ (Naha) ${ }^{9)}$.

With respect to this aspect of damage, we investigated the relationship between the rainfall rate $I_{p}$, defined as the amount of precipitation in ten minutes, and the 10 -min maximum wind speed $V_{m, 10}$ during the passage of a typhoon". Fig. 5 shows the results for Naha, Okinawa Prefecture, in which the wind speed at a height of $z=10 \mathrm{~m}$ above ground is estimated from the measured value at $z=20.6 \mathrm{~m}$ by using a power low exponent of 0.20 . Although there is a scatter in the results, the value of $I_{p}$ has a tendency to increase with increasing $V_{m}, 10$, in particular for $V_{m, 10}>15 \mathrm{~m} / \mathrm{s}$. This feature implies that the damage can be magnified by the rain entering the building significantly.

From the above mentioned discussion, it is strongly recommended that building envelops are designed appropriately, at least with the same probability of failure as the main structural system, in order to reduce the vulnerability of buildings.

\section{ACTIVITIES OF RCWD}

The aims of $R C W D$ are as follows:

(1) Establishment of investigation methods from which useful information can be secured while causing sufferers from disasters and people at stricken areas as little trouble as possible.

(2) Collection, analysis and opening to the public of information of damage caused by strong winds.

(3) Overtures of both the prevention against disasters and the mitigation of the effects and the number of disasters.

(4) Establishment of technology to predict and prevent disasters.

(5) Positive awareness activities for administrative officials and citizens as well as for specialists and implementation of collaborative work.
(6) Establishment of networks for the disaster prevention, extending from municipalities to the world.

To achieve these aims, $R C W D$ is now carrying the following projects into execution.

\subsection{Establishment of CWD NET}

$R C W D$ is working to establish information network (CWD NET) in order to communicate rapidly and efficiently information with respect to wind-induced disasters. In this CWD NET, Japan is divided into six regions and a regional director is appointed to each region, as shown in Fig. 6. These six regional directors and Building Research Institute in Tsukuba as the key station construct the first level network. In some regions, the regional networks have been constructed. The CWD NET is also planned to provide connections to the world in order to exchange global information with respect to wind-induced disasters and its mitigation.

\subsection{Construction of Database of Wind Measurement Conditions}

It is important for investigating wind-induced disasters to obtain wind records of acceptable quality. Since wind-induced disasters may occur anywhere in Japan, $R C W D$ is surveying the existing wind measurement facilities and examining whether the measured data are available. Then, $R C W D$ is now constructing a database of the measurement conditions at each site. The database consists of the following items: 1) institution and the section in charge, 2) location of the observation, 3) details of the instrumentation, 4) setup condition of the anemometer, and 5) conditions of the circumference of the site.

\subsection{Systematization of Investigation of Wind-induced Damage}

In the past, the damage investigations were made by many institutions individually. They used their own damage survey forms and criteria for damage levels. Such a situation sometimes prevented us from understanding the features of the disaster correctly. Furthermore, many people visited the incident office and the stricken areas without any contact with one another. This often disturbed the restoration activities. Therefore, it has been hoped that JAWE would organize a damage investigation team and make a common survey form and criteria 
for damage levels. $R C W D$ is now discussing the manual and survey forms of damage investigation.

\subsection{Contributions to the reduction of wind-induced disasters}

A goal of the above activities of $R C W D$ is to contribute to the reduction of wind-induced disasters. For this purpose, planning of the following actions, among others, are discussed:

(1) Accumulation and analysis of past wind-induced disaster records.

(2) Actions for publicity to the society and local communities.

(3) Guidelines and manuals for disaster prevention.

(4) International cooperation.

\begin{tabular}{|c|l|c|}
\hline BRI & Building Research Institute & Key Station \\
\hline Abbr. & Organization of Regional Director & . Region \\
\hline THU & Tohoku University & Hokkaido, Tohoku \\
\hline NHU & Nihon University & Kanto \\
\hline KYU & DPRI, Kyoto University & Kinki, Chubu \\
\hline TKU & Tokushima University & Chugoku, Shikoku \\
\hline KSU & Kyushu University & Kyushu \\
\hline RYU & Ryukyu University & Okinawa \\
\hline
\end{tabular}

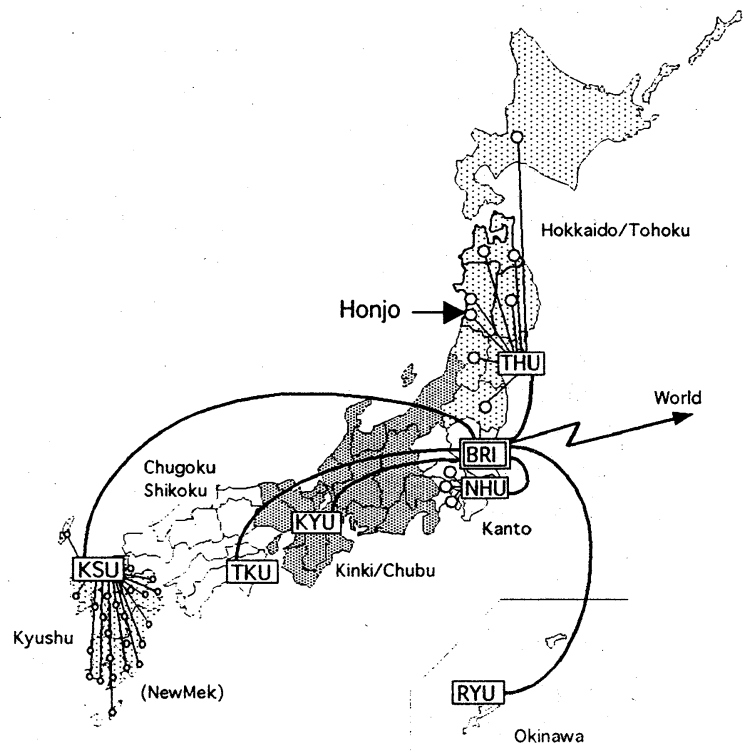

Fig. 6 CWD NET of JAWE.

\section{CONCLUDING REMARKS}

Analyses of wind-induced damage to buildings and structures must be conducted from viewpoints of reducing social economic loss as well as getting lessons for wind resistant design and construction of individual building and structures. In addition, their results must be understood not only by professionals but also by citizens. In order to materialize the recognition, $R C W D$ was organized in JAWE in 1998. The network system for exchanging information or for constructing databases of meteorological measurements and wind-induced damage is growing step by step, and then it will dispatch or catch local and global effective information.

\section{References}

1) T. Ohkuma, Y. Uematsu and T. Nomura: Action programs and systems for reduction of wind-induced disasters conducted by JAWE, Preprints of IFAC Workshop on Control in Natural Disasters CND'98, 1998, pp.151-156.

2) National Astronomical Ovservatory (ed.): Rika Nenpyo (Chronological Scientific Tables), 2000.

3) Y. Tamura: Wind-induced damage to buildings in Japan and countermeasures, Preprints of IFAC Workshop on Control in Natural Disasters CND'98, 1998, pp.157-162.

4) H. Ishizaki, R. Yamamoto, Y. Motsuda and T. Murota: Wind damages to houses due to Typhoon Miyakojima No. 3, Annual Report of Institute of Disaster Prevention, Kyoto University, Vol. 13A, 1970.

5) M. Kawaguchi: Strong wind damage and non-life insurance, J. Wind Eng., JAWE, No. 64, 1995, pp. 49-59.

6) Y. Uematsu, K. Sasaki and T. Nozawa: Survey of wind-damage investigations conducted by municipalities and fire stations and a proposal from a viewpoint of architectural engineering, $J$. Wind Eng., JAWE, No. 83, 2000, pp. 57-64.

7) K. Sasaki and Y. Uematsu: Wind damage to residential houses caused by Typhoon 9119 in Akita and Aomori Prefectures, AIJ J. Technol. Des., No. 9, 1999, pp. 61-64.

8) R.P. Sparks, S.D. Schiff and T.A. Reinhold: Wwind damage to envelopes of houses and consequent insurance losses, J. Wind Eng. Ind. Aerodyn., Vol. 53, 1994, pp.145-155.

9) Y. Uematsu and T. Sone: Stochastic model for predicting the damage to residential houses caused by wind and rain during a typhoon (Part 1 Wind speed and precipitation measured at meteorological observatries), Summaries of Technical Papers of Annual Meeting, AIJ, Structure I, 2000, pp. 113-114.

key words: wind-induced building damage, damage investigation, disaster prevention, network 


\title{
Designing for Typhoons in Hong Kong
}

\author{
K.C.S. Kwok and P.A. Hitchcock \\ CLP Power Wind/Wave Tunnel Facility, Hong Kong University of Science and Technology, Clear Water Bay, \\ Kowloon, Hong Kong, China
}

\section{INTRODUCTION}

Hong Kong is one of the world's most densely populated cities, with nearly all of its seven million population living in high-rise buildings in an area just over $1000 \mathrm{~km}^{2}$. Hong Kong is also situated in an active typhoon region. The high wind speeds caused by typhoons govern the design of tall buildings and other civil structures in terms of safety and strength and the corresponding wind loads are specified in the Codes of Practice on Wind Effects-1983(1). This current wind loading code is in the process of a major revision to bring it up to date by incorporating recent advances in wind engineering.

The hilly terrain of Hong Kong and its high density of tall buildings create significant topographic effects on local wind flow characteristics and hence the design wind loads acting on these tall buildings. Furthermore, the recent trend towards taller, more slender and more flexible commercial and residential buildings, which are more susceptible to wind-induced vibration, highlights the important serviceability design issues of motion perception and occupant comfort. As a result, a wind tunnel model test, including a topographical study in addition to wind load and response predictions, is now routinely employed to assist in the wind resistant design of tall buildings in Hong Kong.

\section{CHARACTERISTICS OF TYPHOON WINDS}

In designing tall buildings, it is necessary to estimate the variation with respect to height of the characteristics of the design wind condition. For tropical climates, where it is necessary to design for typhoon type wind events, there still remains a degree of uncertainty about the structure of a "typical" typhoon, even despite measurements and observations of typhoons over land being reported in several papers ${ }^{(2),}$ (3). A recent review ${ }^{(4)}$ of some typhoon models based on full-scale measurements over open water, which includes a brief discussion on the subject of velocity profile, acknowledges that the relationship between upper level and lower level wind speeds can vary with both radial and circumferential position within a typhoon. For example, estimating just how uniform the vertical profile of mean wind speed is over open water remains an issue unresolved.

Upon reaching landfall, the structure of a typhoon begins to alter due to the change of surface roughness and the loss of the typhoon's energy source, the warm moist air at the surface of tropical oceans, and the diminishing strength of a typhoon has been incorporated into various typhoon models ${ }^{(5)}$, (6). While the progress of a typhoon over land is also very likely to change the vertical profiles of the typhoon, the area of greatest uncertainty remains in the effects of large topographical features, such as mountains, on a typhoon. It should also not be taken as a given that distance from the coast will necessarily result in significant attenuation of wind speed or less wind-related damage. Topographic effects on a typhoon-like wind field have been identified $^{(7)}$ as the cause of wind damages which probably would not have occurred in flat terrain.

\section{THE VULNERABILITY OF HONG KONG TO TYPHOON WINDS}

Although by no means unique in the modern world, the proximity and density of high-rise buildings and other structures in coastal regions of Hong Kong are major factors in their wind-resistant design, and in particular their ability to withstand typhoon events. However, the significant topography of Hong Kong, and its proximity to areas of considerable high-rise development, is another factor which further complicates the potential effects of typhoon winds on local buildings, and which has at least been recognised in the current local design $\operatorname{code}^{(1)}$.

The mountain range spanning Hong Kong Island runs approximately east-west, and has a number of 
peaks in excess of $500 \mathrm{~m}$ above sea level. A short distance away to the north across Victoria Harbour, Kowloon Peninsula is surrounded by mountains with peaks up to $700 \mathrm{~m}$. Both regions are home to a large number and high density of medium-rise to high-rise buildings and other civil structures. That the major built-up areas on Hong Kong Island and Kowloon Peninsula are in relatively close proximity to significant mountain ranges will have a major impact on local wind fields for winds from certain directions. For example, strong winds coming from southerly directions over Hong Kong Island speed up as they pass over the mountains, which will directly affect structures on its southern side. Furthermore, the sudden, sharp declines of Hong Kong's peaks cause flow separation and a significant drop in mean wind speeds, apparently providing a sheltering effect to the buildings of the CBD along the northern waterfront, as shown in Figure 1. However, the lower mean wind speeds do not provide a complete picture of the magnitude of the wind loads which may be experienced. The increased turbulence intensity in these zones of flow separation, and the physical size of the vortices mean that gust wind speeds may still be quite large and that wind gusts may also be better correlated over large areas of a building or structure. This may be offset to some degree though due to the density of the built environment on Hong Kong Island.

Further downstream, across Victoria Harbour on Kowloon Peninsula, the medium-rise to high-rise buildings are likely to lie outside the zone of separation caused by Hong Kong Island's topography. For southerly winds, this will result in relatively high turbulence intensity due to the influence of Hong Kong Island. The mountain ranges surrounding Kowloon Peninsula are also likely to cause similar effects for other wind directions, although to varying degrees due to their proximity, height, and the surrounding dense medium-rise structures.

In assessing the hazard represented by typhoon events in Hong Kong, there are understandably a number of factors which will be highly site specific, several of which are relatively poorly defined and/or understood at present. The ability of Hong Kong buildings to resist typhoon wind loads can be attributed to the current design wind speeds; which err on the side of conservatism, and the location of buildings which are potentially the most vulnerable. Due to the conservatism of the design wind speeds, the structural systems of properly designed buildings are likely to be able to withstand the large wind loads which will arise in a severe typhoon. However, the vulnerability of individual elements and cladding for example may be higher due to the quality of construction, the use of various types of materials, and the physical location of a building. Although new tall building developments in Hong Kong are often submerged in already built-up areas, through necessity of limited available land, economic and architectural influences, and even the aerodynamic effects of neighbouring buildings, there may be significant exposure to higher than expected hazard and/or vulnerability. While Typhoon York recently highlighted several of these potential issues, it should be realised that no fully glazed building in Hong Kong has yet been subjected to the wind forces associated with a severe typhoon.

A current common approach to better assessing the wind field for a particular structure is through wind tunnel testing. While the physical modelling of a subject building, the surrounding buildings and topography will potentially provide a more accurate representation of the wind loads acting on a structure, a number of uncertainties remain in modelling typhoon characteristics. In order to model the basic wind characteristics at a particular site so that the variation of mean and gust wind speed is simulated over the height of a building, one can undertake topographic studies in the wind tunnel. However, the results from these studies will only be as accurate as the approach conditions modelled in the wind tunnel, which are limited by the uncertainties in estimating the approach characteristics for example. Wind tunnel topographic studies are also generally undertaken at relatively small scales (ie less than 1:1000); making it difficult to simulate the approaching vertical profiles and the surface roughness of a subject site, and are almost always undertaken in neutral conditions. This takes on particular significance when designing wind-sensitive structures and/or very tall buildings in excess of $400 \mathrm{~m}$. The magnitude and uniformity of wind speed and turbulence intensity profiles over the height of the building will have a critical effect on the building's response.

The topography of Hong Kong will also interact with typhoons in other less certain ways. It is generally accepted that the turbulence intensity of typhoons is higher than for non-typhoon winds due to the convective instability that exists in typhoons ${ }^{(8)}$. This instability also results in significant vertical air movements during typhoons, the consequences of which, when mixed with rough terrain and high mountains, are not clearly understood.

There will inevitably be a variety of pressures to review design wind speeds and codified wind characteristics, even in the face of recognised conservatism. A thorough and rigourous process is needed to incorporate the latest available data and knowledge in the codification process to 
accommodate an acceptable level of risk through a better understanding of the wind hazard associated with typhoons.

\section{CODE OF PRACTICE ON THE DESIGN OF BUILDINGS FOR WIND EFFECTS}

The design of buildings for wind effects is currently governed by the Code of Practice on Wind Effects Hong Kong- $1983^{(1)}$, published by the Buildings Department (the then Building Authority). The current 1983 edition of the wind code superseded the 1976 edition. The code specifies design peak gust wind velocities and the corresponding design wind pressures as a function of height above ground. For a return period of 50 years, the design gust wind speed is $84 \mathrm{~m} / \mathrm{s}$ at the gradient height, which is assumed to be $250 \mathrm{~m}$ above ground for a general terrain and $300 \mathrm{~m}$ for a built-up terrain. The format of the code, the calculation procedure and the various coefficients and constants are mostly adopted from the British Standard BS CP 3: Chapter V: Part 2: $1972^{(9)}$. Essentially, the wind load is estimated based on a quasi-steady approach. The effect of a change in ground roughness, between general terrain and built-up terrain, is accounted for using a developed height approach. While an adjustment to the artificial base level for assigning the wind load distribution is given for buildings located on slopes, to account for speed up effects, no guideline is given for other significant topographical effects. Simple guidelines are also given for dynamic effects for wind-sensitive buildings and structures.

A Practice Note for Authorized Persons and Registered Structural Engineers, PNAP $150^{(10)}$, was published by the Buildings Department, first in 1991 and revised in 1994, to provide guidance on wind tunnel testing of buildings, which have increasingly been employed for the design of tall buildings and other civil structures in Hong Kong. The recommendations contained in PNAP 150 emphasize the importance of correct modelling of the mean wind velocity and turbulence intensity profiles for terrain type, instrumentation characteristics, Reynolds number effects, dynamic effects of buildings, local topographical effects, and interference by adjacent buildings. It further specifies a mean hourly design wind speed of $64 \mathrm{~m} / \mathrm{s}$ at gradient height.

The wind climate of Hong Kong, particularly the magnitude of design wind speeds, has been the subject of a number of detailed studies ${ }^{(11),(12)}$. More recently, a comprehensive study of the Hong Kong wind climate and the effects of topography has been undertaken based on a 1:400 scale model study of the flow field around Waglan Island and a 1:2000 scale topographic model of the HKSAR. The results of the re-analysis of typhoon wind records up to 1999 using a "peaks over threshold" approach are reported in a separate paper in this conference ${ }^{(13)}$. In summary, the results reinforce early findings of Davenport et al. (1984) $)^{(11)}$ and Melbourne (1984) $)^{(12)}$ that the 50-year return period mean wind speed is much less than the value suggested in PNAP $150^{(10)}$ at gradient height.

In the past two decades since the last revision of the Hong Kong wind code in 1983, there have been many advances in the understanding of wind characteristics and the dynamic effects of wind on structures. Many of these advances have been successfully adopted in a number of advanced wind codes worldwide. In line with recent revisions of the wind code in a number of countries including Australia/New Zealand, Canada, China; UK and USA, an ad hoc committee has been formed to modernise the Hong Kong wind code, in consultation with local practising engineering consultants and government departments. Areas deserving special attention include the following:

- Wind velocity and turbulence profiles for monsoon and other strong winds, and for typhoons;

- Design wind speeds;

- Dynamic effects, both alongwind and crosswind, for wind sensitive structures;

- Topographical effects;

- Occupant perception of motion and occupant comfort assessment; and

- Guidelines on wind tunnel model studies.

\section{CONCLUDING REMARKS}

High design wind speeds associated with typhoons, complex topography, high concentration of tall buildings, and growing expectation of superior serviceability performance pose significant challenges in the wind resistant design of tall buildings in Hong Kong. An updated wind loading code and state-of-thc-art wind tunnel model testing techniques, which incorporate recent advances in wind engineering, will provide the platform for an economical design of the next generation of tall buildings in Hong Kong.

\section{ACKNOWLEDGMENTS}

The authors thank Dr Greg Chiu for his valuable comments and suggestions during the preparation of this paper. The work presented in this paper is partly supported by a Hong Kong University of Science and Technology Direct Allocation Grant (DAG98/99.EG37). 


\section{REFERENCES}

(1) Building Development Department, Hong Kong, Code of Practice on Wind Effects, Hong Kong, (1983).

(2) Amano, T., Fukushima, H., Ohkuma, T., Kawaguchi, A. and Goto, S., The observation of typhoon winds in Okinawa by Doppler Sodar, Journal of Wind Engineering and Industrial Aerodynamics, 83, pp. 11-20, (1999).

(3) Xu, Y.L. and Zham, S., Field measurements of Di Wang Tower during Typhoon York, Journal of Wind Engineering and Industrial Aerodynamics, 89, pp. 73-93, (2001).

(4) Wills, J., Wyatt, T., and Lee, B., Warnings of high winds in densely populated areas, published for the UK National Coordination Committee for the IDNDR by Thomas Telford Publishing, (1998).

(5) Georgiou, P.N., Design wind speeds in tropical cyclone-prone regions, $\mathrm{PhD}$ thesis, University of Western Ontario, London, Ontario, (1985).

(6) Vickery, P.J. and Twisdale, L.A., Wind-field and filling models for hurricane wind-speed predictions, ASCE Journal of Structural Engineering, 121(11), pp. 1700-1709, (1995).

(7) Walker, G.R., Reardon, G.F. and Jancauskas, E.D., Observed effects of topography on the wind field of Cyclone Winifred, Journal of Wind
Engineering and Industrial Aerodynamics, 28, pp. 79-88, (1988).

(8) Sharma, R.N. and Richards, P.J., A reexamination of the characteristics of tropical cyclone winds, Journal of Wind Engineering and Industrial Aerodynamics, 83, pp. 21-33, (1999).

(9) British Standard BS CP 3: Chapter V: Part 2: 1972.

(10) Practice Note for Authorised Persons and Registered Structural Engineers PNAP 150.

(11) Davenport, A.G., Georgiou, P.N., Mikitiuk, M., Surry, D. and Kythe, G., The wind climate of Hong Kong, Proceedings of the Third International Conference on Tall Buildings, Hong Kong and Guangzhou, pp. 454-460, (1984).

(12) Melbourne, W.H., Design wind data for Hong Kong and surrounding coastline, Proceedings of the Third International Conference on Tall Buildings, Hong Kong and Guangzhou, pp. 461-467, (1984).

(13) Holmes, J.D., Hitchcock, P., Kwok, K.C.S. and Chim, J., Re-analysis of Hong Kong typhoon wind speeds using the 'peaks over threshold' approach, Proceedings of the Fifth Asia-Pacific Conference on Wind Engineering, Kyoto, Japan, (2001).

Key words: Typhoons, Tall buildings, Topography, Wind tunnel, Wind code.

Figure 1: Topographic effects on local wind characteristics, Central, Hong Kong

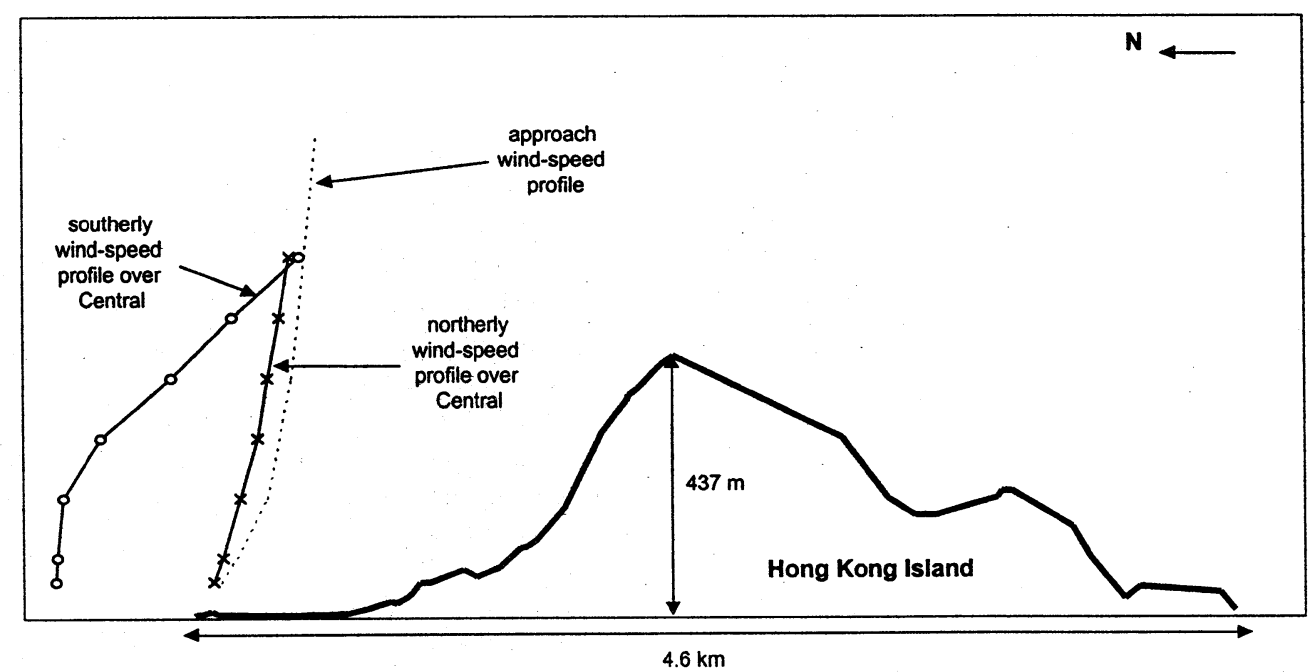




\title{
An Application of the Typhoon Simulation Model to the Insurance Industry
}

\author{
Hiroyuki Watabe and Masaru Matsumoto"1 \\ 1) Research \& Development Group, The Tokio Marine Risk Consulting Co.,Ltd., Mihama-ku Chiba, Japan
}

\section{Introduction}

Japan is not only known for the fact that it is an Earthquake country, but it is also as a highly Typhoon prone country. From 1951 to 2000,1320 typhoons formed in the Pacific. Of those, 143 made landfall on the mainland of Japan. Infrequently every ten to twenty years, severe typhoons make landfall causing catastrophic losses to Japanese property \& casualty insurance companies. In 1991, a typhoon named Mireille with a central pressure of $940 \mathrm{hpa}$ made landfall in Sasebo City, passed over Kyushu, and proceeded over the Sea of Japan to head up to the northeast of mainland Japan. Mireille caused an excess of US $\$ 6$ Billion to the insurance industry. And in 1999, typhoon Bart with a central pressure of 945hpa made landfall in Ushibuka-City of Kyushu, the southern Island of Japan, causing US $\$ 3$ billion in damage. Kyushu is known as a highly typhoon prone area. The loss paid due to recent intense windtyphoon is shown in Table 1.

In 2000, there was no typhoon that made landfall on the mainland of Japan. However, if the intense typhoon Kirogi took a course slightly east of its original track, thereby touching Tokyo and passing the Metropolitan area which is a highly value concentrated area, insurers could have suffered heavy losses. The year of 2000 was considerable to be quite uneventful with regards to typhoon damage and loss, however the situation still remains highly volatile for insurers.

Most of damaged objects due to windstorm are residential and commercial buildings, household goods, automobiles etc. Normally these properties are covered by fire insurance policy or automobile insurance policy etc. The type of loss for residential buildings is mainly petty claim such as scattering of

Table 1

Recent Intense Typhoon Losses

\begin{tabular}{|c|c|c|c|c|c|c|c|c|}
\hline \multirow[b]{2}{*}{ Year } & \multirow[b]{2}{*}{$\begin{array}{l}\text { Typhoon } \\
\text { Number }\end{array}$} & \multirow[b]{2}{*}{$\begin{array}{c}\text { Typhoon } \\
\text { Name }\end{array}$} & \multicolumn{2}{|c|}{ Fire Insurance Policy } & \multicolumn{2}{|c|}{ Other Insurance Policy } & \multicolumn{2}{|c|}{ Total } \\
\hline & & & $\begin{array}{l}\text { Number of } \\
\text { Paid Policy }\end{array}$ & $\begin{array}{c}\text { Total Paid } \\
\text { Amount } \\
\text { (Billion Yen) }\end{array}$ & $\begin{array}{l}\text { Number of } \\
\text { Paid Policy }\end{array}$ & $\begin{array}{c}\text { Total Paid } \\
\text { Amount } \\
\text { (Billion }\end{array}$ & $\begin{array}{l}\text { Number of } \\
\text { Paid Policy }\end{array}$ & $\begin{array}{l}\text { Total Paid } \\
\text { Amount } \\
\text { (Billion Yen) }\end{array}$ \\
\hline 1990 & 9019 & Flo & 280,000 & 29 & 25,000 & 3 & 305,000 & 32 \\
\hline 1991 & 9119 & Mireille & $4,847,000$ & 498 & 126,000 & 25 & $4,973,000$ & 523 \\
\hline 1993 & 9313 & Yancy & 934,000 & 86 & 42,000 & 8 & 976,000 & 93 \\
\hline 1998 & 9807 & Vicki & 147,526 & 144 & 7,772 & 7 & 155,298 & 151 \\
\hline 1999 & 9918 & Bart & 221,600 & 195 & 5,162 & 10 & 226,762 & 205 \\
\hline
\end{tabular}


roof coverings, broken windows by debris hitting, etc. Table 2 shows that $98 \%$ of the wind damages are slight damage. For residential buildings, if the losses exceed 200,000 yen per fire insurance policy, the policy fully covers petty losses from the bottom up. The accumulation of these petty losses heavily impacts on the insurance business.

Table 2 Degree of damage for building by Mireille

\begin{tabular}{|c|c|r|}
\hline $\begin{array}{c}\text { Degree of } \\
\text { Damage }\end{array}$ & $\begin{array}{c}\text { Number of Damaged } \\
\text { Residential Buildings }\end{array}$ & \multicolumn{1}{c|}{ Ratio } \\
\hline Slightly & 665,616 & $97.9 \%$ \\
Moderate & 13,482 & $2.0 \%$ \\
Extensive & 1,056 & $0.2 \%$ \\
\hline Total & 680,154 & $100.0 \%$ \\
\hline
\end{tabular}

The main problems facing insurers due to catastrophic typhoon remain the uncertainties of typhoon occurrence and varying degrees of loss amount. These uncertainties make the task of insurers, who manage typhoon risk, very difficult and complex. Also insurance record does not contain significant detail that can provide actuarially credible information about potential future typhoon loss.

Recent advances in computer technology and data analysis, as well as better scientific understanding of typhoons, have greatly expanded the tools available to help insurance companies understand and manage their hurricane risk in the U.S. We, at the Tokio Marine Risk Consulting Company, developed the computer based catastrophic model for typhoon risks in Japan. Profs. Mitsuta and Fujii had statistically analyzed the landfall data of the intense typhoons, and they statistically generated huge numbers of intense typhoons using the Monte-Carlo simulation technique ${ }^{3)}$. After that they estimated the return period of gust wind speed at a particular point. Our model is also based on their approach, and estimation of the loss for insurance policies due to gust wind speed are based on our huge number of historical claim data.

\section{Procedure}

The model consists of the components of Hazard and Damage.

\section{2-1. Hazard}

\section{2-1-1. Generating Stochastic Typhoon Event}

About 60 intense typhoons making landfall on the mainland of Japan for 50 years are analyzed to determine the statistical characteristics of the typhoon parameters at the landing time. Followings are the parameters for analysis; landing position, central pressure, translation speed, landing angle and the radius of the maximum wind speed. For analysis purpose, the western part of Japan is divided into four areas; West-Kyusyu, East-Kyusyu, West main land (Cyugoku-Kinki) and East main land (Kanto) followed by previous study ${ }^{4) 5}$. The parameters are analyzed for each area. Fig.1 is an example of the plotting the difference between central pressure and ambient pressure on log-normal probability paper. The data fit the distribution well over most of the range.

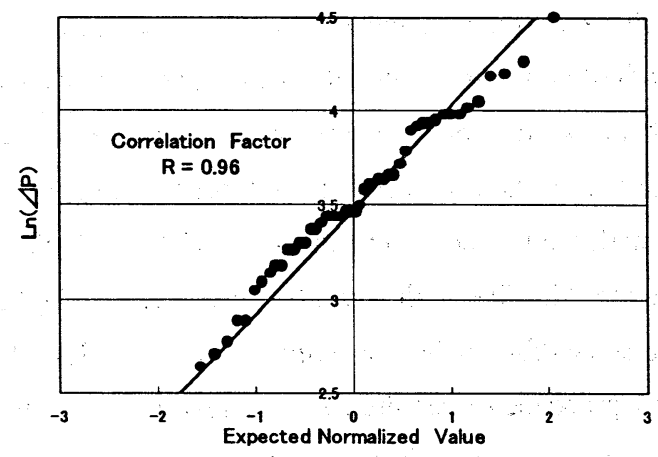

Fig. 1 An example of analysis of central pressure. After analysis of these parameters, we stochastically generate the typhoon based on the set of parameters from each parameter distribution using the MonteCarlo technique.

Table 3 Distribution of Typhoon Parameters

\begin{tabular}{|c|c|}
\hline Parameters & Distribution \\
\hline Landing Point & Uniform \\
Differential Pressure $(\Delta \mathrm{P})$ & Log Normal \\
Translational Speed $\quad(\mathrm{C})$ & Log Normal \\
Angle ( $\alpha)$ & Normal \\
Radius of Max. Wind Speed (Rm) & Log Normal \\
\hline
\end{tabular}

Annual landfall frequency is assumed three times per year, and the location of landfall is determined by the 
Poisson process with the length of coastline. Table 3 shows the suitable distribution pattern for the parameters. An example of generated storm tracks for 30 years is shown in Fig.2

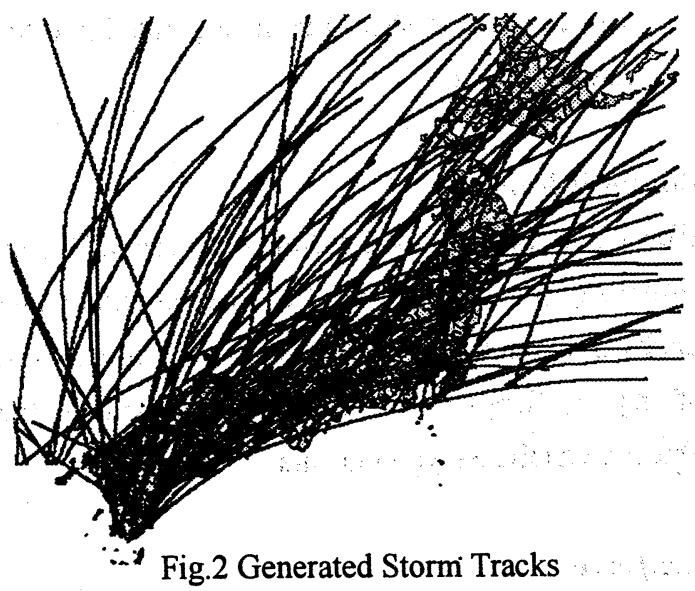

\section{2-1-2. Estimation of Gust Wind Speed}

The gust wind speeds at the points of interest are calculated using generated storm tracks with some typhoon parameters. The method of gust wind speed estimation is based on the Mitsuta-Fujii's model ${ }^{3)}$.

The radial distribution of surface pressure for a given case is then compared to the following expression:

$$
\mathrm{P}(\mathrm{r})=\mathrm{P}_{0}+\Delta \mathrm{p} \exp (-\mathrm{A} / \mathrm{r})
$$

where $P(r)=$ surface pressure at a distance $r$ from the storm center; $\mathrm{P}_{0}=$ central pressure; and $\mathrm{A}=$ location parameter.

$$
1 / \rho * \mathrm{dP} / \mathrm{dr}=\mathrm{Vgr}^{2} / \mathrm{r}+\mathrm{f} \mathrm{Vgr}
$$

where $\mathrm{Vgr}=$ gradient wind speed; $\mathrm{f}=$ Coriolis parameter; and $\rho=$ air density. To account for the asymmetry in wind speeds resulting from the storm translation speed, Blaton's adjusted radius of curvature is used

$$
r_{\mathbf{t}}=r /(1-c / V \sin (\alpha))
$$

where $\mathrm{c}=$ translation speed, $\alpha=$ angle (positive clockwise) from the storm translation direction to the profile location. Substituting (1) into (2) and replacing $r$ with $r_{t}$ leads to the following expression for gradient wind speeds:

$$
\mathrm{Vgr}=1 / 2(\mathrm{c} \sin (\alpha)-\mathrm{fr}))
$$

$$
+\left(1 / 4(\mathrm{c} \sin (\alpha)-\mathrm{fr})^{2}+\Delta \mathrm{P} / \rho(\mathrm{A} / \mathrm{r}) \exp (-\mathrm{A} / \mathrm{r})\right)^{1 / 2}
$$

Surface wind speed (Vs) is

$$
\mathrm{Vs}=\mathrm{G}(\mathrm{x})^{*} \mathrm{Vgr}
$$

where $G(x)$ is the function between Vgr and $V s^{6}$.)

The gust wind speed (Vmax) is

$$
\mathrm{Vmax}=\mathrm{G}^{*} \mathrm{Vs}
$$

where $G$ is the gust factor, which is the averaged value of observed data at Japan Meteorological Agency's observation stations during typhoon Mireille.

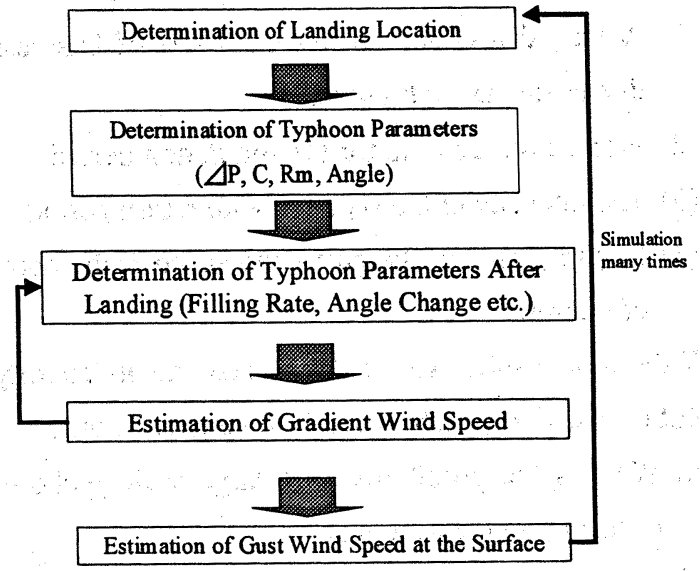

Fig.3 Flow of Producing Gust Wind Speed

\section{2-2. Damage Component}

The claim data due to recent catastrophic typhoons were analyzed, and the exponential relationships between paid loss amount and estimated gust wind speed were observed :

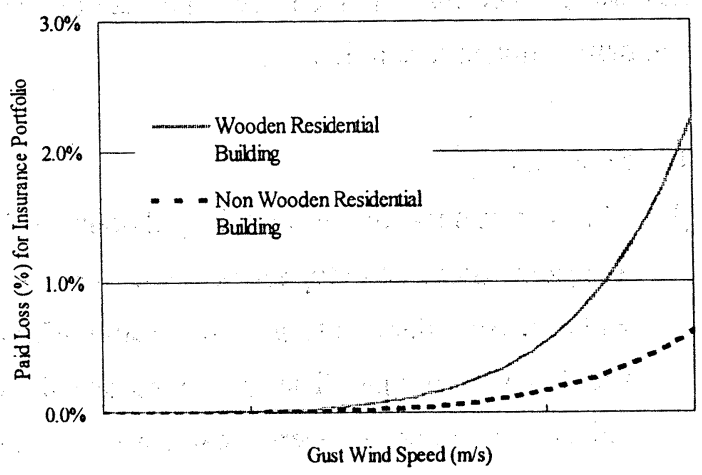

Fig.4 An example of loss function

An example is shown in Fig.4 for typical residential buildings, in which wind loss occurs at around $30 \mathrm{~m} / \mathrm{s}$. 
Various types of loss functions were developed for the type of objects and line of insurance.

\section{Application to insurance business}

The typhoon simulation model can be applied to our portfolio not only for fire insurance but also for other lines of insurance covering wind damage. By extending the simulation period to great many years, we can obtain many cases of the simulated loss amount by each stochastic typhoon event. Following results are produced by the catastrophic model.

(1) Averaged loss amount for each line of business due to stochastic typhoon

(2) Worst case scenario for the simulation period

(3) The intensity of the typhoon with return period

(4) Return period of the gust wind speed at the point of interest

With these results, we are able to take the uncertainty out of questions, such as the following questions:

a) What is the possibility of a large scale typhoon occurring in the next year?

b) Will our insurance premiums provide enough coverage for future typhoon strikes?

c) Will our reserves for extraordinary loss due to typhoon be enough?

This catastrophic typhoon model will help insurer to structure their plans to spread risk with reinsurance, risk swap, securitaization etc. for maintaining the company's financial stability.

\section{Summary}

(1) The parameters of historical typhoons were analyzed. Stochastic typhoons were generated with these data using the Monte-Carlo simulation technique. The gust wind speeds at points of interest were calculated using generated stochastic events.

(2) The loss function that is the relationship between paid loss amount and gust wind speed was developed for lines of insurance.
(3) With these data, we analyzed our insurance portfolio.

(4) However our model is just considered for wind damage by typhoon. The estimation of the flood loss component should be incorporated into the future models.

\section{Acknowledgements}

We would like to thank Dr. Taiich Hayashi of Kyoto University for supporting the typhoon simulation model development, and also thank Dr. Takeshi Fujii of Kyoto Sangyo University for providing the objective analyzed typhoon data.

\section{Reference}

1) The Marine \& Fire Insurance Association of Japan Inc. Periodical Publication (in Japanese)

2) Fire Disaster Management Agency Periodical Publication (in Japanese)

3) Mitsuta,Y. and Fujii T., "Synthesis of Typhoon Wind Patterns by Numerical Simulation" Natural Disaster Science, Vol.8, Number 2, 1986. pp.4961

4) Mitsuta, Y. Fujii T.and K.Kawahira, "Analysis of Typhoon Pressure Patterns over Japanese Islands “ Natural Disaster Science, Vol.1, Number 1, 1979. pp.3-19

5) Mitsuta,Y. and Fujii T., "Analysis of Typhoon Pressure Patterns over Japanese Islands (II) “ Natural Disaster Science, Vol.8, Number 2, 1986. pp.19-28

6) Mitsuta,Y. etal. "A Predicting Method of Typhoon Wind Damages", Proceeding of the Seventh Specialty Conference on Engineering Mechanics and Structural Divs./ASCE, 1996. pp.970-973

Key Words: Insurance, Typhoon, Paid Loss, Loss Function, Monte-Carlo Simulation 